\title{
ПРАГМАЛИНГВИСТИЧЕСКИЙ ПОДХОД К ДЕЛОВОЙ ПРЕЗЕНТАЦИИ
}

\section{PRAGMALINGUISTIC APPROACH TO BUSINESS PRESENTATION}

Yu. Medvedeva

Summary: The article considers the pragmalinguistic content of business presentation. It describes the views on presentation as a kind of discourse and as a speech genre in the modern linguistics. A sample of presentation is examined from the perspective of a five-component model containing pragmatic (theme, style, intention) and linguistic (composition, lexis) elements. Special attention is paid to the analysis of the speech strategies typical of the examined genre, namely presentation, convention and persuasiveness, and to the tactics of their implementation.

Keywords: business presentation, speech genre, mixed verbal and nonverbal communication, presentation strategy, speech tactics.
$\mathrm{M}$ ассово-информационное общение, важнейшей характеристикой которого является такой способ подачи материала, который представляет собой «демонстрацию смыслов», является сегодня ведущим типом дискурса, оказавшим влияние практически на все типы институционального общения [8, с. 3]. В настоящее время деловые презентации, осуществляемые как в реальном, так и в виртуальном пространстве, становятся всё более распространенными, навыки деловой презентации всё более востребованными, что определяет актуальность данного исследования.

В современной парадигме языкознания речь и общение изучаются с позиций дискурса, деловая презентация рассматривается как разновидность делового дискурса. Деловой институциональный дискурс, при этом, характеризуется определённым комплексом норм, стереотипов мышления и поведения, присущим участникам данного института, и проявляющимся в форме экстралингвистических факторов типичных речевых ситуаций. Внутри дискурса деловой презентации создаются речевые произведения, которые имеют особую прагматику и преследуют определённые цели, обращены к определённому адресату и характеризуются некоторой стереотипностью. «Коммуникативные клише в рамках институционального дискурса выступают как своеобразные ключи для понимания всей системы отношений в соответствующем институте и могут быть смоделированы» $[2]$.

С прагмалингвистических позиций дискурс дело-
Медведева Юлия Ивановна

Старший преподаватель, Финансовый университет при Правительстве Российской Федерации (Москва) Tea4english@yandex.ru

Аннотация: В статье рассматривается прагмалингвистическое содержание деловой презентации. Описываются подходы к деловой презентации в современном языкознании как к дискурсу и как речевому жанру. Исследуется образец презентации с позиций пятикомпонентной модели, включающей прагматические (тема, стиль, интенциональность) и лингвистические (композиция, лексика) элементы. Особое внимание уделяется анализу таких характерных для представленного жанра речевых стратегий, как презентация, конвенция и персуазивность, и тактик их реализации.

Ключевые слова: деловая презентация, речевой жанр, вербально-невербальная коммуникация, презентационная стратегия, речевые тактики.

вой презентации может рассматриваться как комплекс следующих элементов: адресант, интенция, текст, интерпретанта, адресат. Адресант и адресат предстают во всей полноте своих социальных и психологических ролей, пресуппозиций, личностных характеристик и т.п. Их роли активные, требующие как речевых, так и неречевых действий, как в ходе коммуникативного акта, так и за его пределами. Коммуникативное намерение (интенция) адресанта противопоставляется интерпретанте адресата, которые выступают в данной схеме как прагматические составляющие плана содержания текста, его прагматические значения [3]. Следовательно, к прагматике дискурса относятся не только коммуникативные намерения и цели (в терминах теории речевых актов, иллокуция), но и произведённый эффект, интерпретация, ответная реакция (перлокуция).

Вместе с тем, в настоящее время множество исследований, посвящённых типам дискурса, опираются на теорию речевых жанров. Так, например, согласно Е.П. Буториной, институциональный деловой дискурс представлен системой речевых жанров, актуальных при общении субъектов коммуникации в сфере деловых отношений [2]. Дискурс рассматривается как система дискурсообразующих жанров, под которыми понимаются «генерализованные и стандартизированные формы дискурсивной деятельности, в рамках которых функционируют традиционные <...> речевые жанры» [7, с. 9]. Таким образом, презентация рассматривается как жанр делового дискурса (С. В. Оленев, Н.А. Ширкина), как жанр PRдискурса (Е.А. Козлова; О.Ф. Русакова, В.М. Русаков), как 
жанр, являющийся составной частью деловых переговоров (Н.А. Баландина).

Согласно В.В. Дементьеву, речевой жанр в настоящее время является базовой единицей:

1. анализа дискурса;

2. изучения коммуникативной компетенции (жанровая компетенция является её значимой частью);

3. языковой и коммуникативной картины мира;

4. портретирования языковой личности (владение речевыми жанрами связывается со статусными характеристиками личности) [5].

К научному описанию модели речевого жанра существует масса подходов, однако все они опираются на положения концепции, восходящей к идеям М.М. Бахтина и его модели речевого жанра в триединстве темы, стиля и композиции [4; 6]. В данной работе мы применяем пятикомпонентную модель, включающую тему, стиль, интенциональность, композицию и лексическое наполнение речевого жанра, где первые три являются прагматическими характеристиками, поскольку учитывают такие важнейшие параметры, как ситуация и сфера общения, характеристики и интенции коммуникантов, а последние два лингвистическими, т.к. относятся к формам речи, «в том числе способам оформления начала и конца речи, передачи инициативы в диалоге, стратегиям и тактикам ведения коммуникации» [5; с. 7]:

- тема речевого жанра, т.е. предмет речи, включая контекстуальный и аксиологический фактор, относительно чего возникает ответная реакция;

- стиль жанра, выражающий определённую (экспрессивную) позицию адресанта и определяющий ответную позицию адресата;

- интенциональный фактор: «идентификация и характеристика жанра, социально-ролевой структуры и контекста на иллокутивно-целевой основе» [6, с. 84];

- композиция жанра, представляющая собой определённые типы построения целого и обеспечивающая связь темы и стиля с действительностью [4];

- лексическое наполнение жанра, включая речевые клише и языковые средства реализации определённых речевых тактик для осуществления интенций.

Стандартными темами деловой презентации выступают представление проекта, программы, продукции, услуг, представление компании, предъявление бизнесстратегии. При этом, значимость сообщаемой информации связана с аксиологическим контекстом, т.е. оценкой говорящего. Ввиду того, что, как правило, субъект коммуникации положительно оценивает предъявляемые им идеи, представление в формальном и аналитическом стиле может быть лишено экспрессивных элементов, но содержать положительную оценку имплицитно.
Стилистический аспект выступления определяет учёт статусно-ролевых характеристик говорящего и аудитории и характера их взаимодействия (деловые партнёры (действующие или потенциальные), вышестоящие и нижестоящие сотрудники, равные по статусу коллеги, взаимодействие между представителями организации и потребителями, клиентами и т.д.).

Согласно В.В. Дементьеву, параметры ситуаций дискурса чрезвычайно многообразны, а, следовательно, так же многообразны соответствующие типы жанров [5]. Поскольку лингвистическое наполнение жанров презентации зависит от конкретных прагматических характеристик, проанализируем образец презентации со следующими прагматическими параметрами: выступающий - разработчик программного обеспечения Mario Peshev; тема презентации - представление программного продукта на конференции BG PHP Conference 2015, посвящённой инновационным разработкам в сфере программирования, аудитория которой - профессиональное сообщество; стиль, которого придерживается говорящий, полуофициальный.

Рассматриваемый пример жанра имеет стереотипное структурное оформление: представление себя, представление цели и темы презентации, предъявление плана презентации, основная информация, заключение/ выводы, побуждение к дальнейшим действиям, обсуждение возникших вопросов и комментариев. Каждая композиционная часть характеризуется определёнными дискурсивными формулами (клише):

1. представление себя и цели презентации: Hi everyone. Yeah, as Michael said I'm Mario Peshev and I'm going to talk about WordPress which is a popular topic normally in a bit different context, so what I'm going to talk about is actually Code Architecture.

2. предъявление плана презентации: I'm actually going to touch on some decisions that were made by the WordPress core team $<\ldots$... including some of the factors why WordPress is what it is right now, some frontend ideas and concepts of the engine itself.

3. предъявление основной части презентации, демонстрация идей: Before we start what I'm going to talk about it's personal opinion about different platforms...; So regarding good code...; Now on the front end this is the diagram of the WordPress templating engine;

4. заключение, выводы, побуждение к дальнейшим действиям, обсуждение возникших вопросов и комментариев: And that's all from me. The only thing I would like to say at the end is think about what you're using, think about what you've been using $<\ldots>$. Thank you.

Презентацию типично относят к речевым ситуациям монологического типа (В.С. Григорьева). Согласно 
М.Я. Блоху, в современном философском языкознании бытует положение о том, что речь по своей сути всегда диалогична, поскольку всегда кому-то предназначена, но в этом положении адресованность речи, как её имманентное свойство, подменяет понятие обмена репликами в диалоге. «Речь, нацеленная на вызов реплики, тем самым есть составная часть диалога $\langle\ldots . .>$, а речь, не нацеленная на вызов реплики, есть составная часть монолога» [1, с. 54-55]. Таким образом, заключительная часть композиции, в которой выступающий побуждает аудиторию к выражению ответной реакции отличается от остальных частей диалогичностью: Just listen, let it sink and we can discuss some things later on, some of your ideas or your feedback.

Интенциями субъекта выступления являются информирование, убеждение, формирование у профессионального сообщества, коллег, потребителей новых ценностных ориентаций, изменение их личностных установок, взглядов, намерений, переориентация целей в профессиональной деятельности. «Действия субъекта воздействия направлены на решение двух групп задач: первая группа - задача организации общения (привлечение и удержание внимания, создание благоприятной атмосферы, эмоционального настроя и т.д.), вторая группа задач связана с оказанием собственно воздействия» [9, с. 175]. Для достижения указанных задач в дискурсе деловой презентации применяются презентационная, конвенциональная и персуазивная стратегии.

Жанр деловой презентации, заимствуя термин А.В. Олянича, можно назвать смешанной вербально-невербальной коммуникацией, под невербальными средствами, при этом, понимаются кинесические и проксемические образования [8]. В ракурсе данного исследования к этой категории относится и такая невербальная визуальная опора, как схемы, графики, изображения, содержащиеся в презентационных слайдах. Кроме того, презентация представляется смешанной и с точки зрения формы речи, так как публичное выступление сопровождается тезисами на презентационных слайдах. Подобные характерные особенности исследуемого дискурса играют значительную роль в реализации указанных стратегий.

Презентационная стратегия, на наш взгляд, осуществляется с целью информирования, эффективной демонстрации смыслов и идей с применением как невербальных (слайды, движения, жестикуляция), так и вербальных средств (We can do dynamic expressions as part of static class course [pointing at the screen]; This is the diagram of the WordPress templating engine [showing the diagram on the slide]), включая перефразирование и уточнение (So what I'm trying to say here is that...) и использование метакоммуникативных и перформативных речевых актов в качестве тактики прямой коммуникации, средства управ- ления содержательной и композиционной сторонами текста, эксплицирования, уточнения и подчёркивания интенций: Before we start what I'm going to talk about it's personal opinion about different platforms that I've used out there, different projects that we've built over the years. So keep in mind that no flame intended. Like I'm pretty sure that tomatoes are going to head my way and I'm going to hide here [hiding behind the chair]. So keep that in mind I'm going to be prepared [smiling]. And just listen, let it sink and we can discuss some things later on, some of your ideas or your feedback.

Следует отметить, что последний пример, в котором выступающий в шутливой манере предупреждает о возможном возникновении противоречивых мнений и даёт инструкции аудитории о поведении в ходе презентации, также способствует реализации конвенциональной стратегии, целью которой является управление ситуацией через взаимодействие и согласование поведения участников с целью достижения договорённости, или конвенции. Следовательно, метакоммуникативные высказывания являются средством реализации как презентационной, так и конвенциональной стратегии. В рамках последней также применяется тактика подчеркивания общих пресуппозиций, взглядов, интересов, целей благодаря переходу от "уоu" к "we": I urge you to think about that using your specific platform or framework $<\ldots$. > or whatever you are using. There are simply different ways to solve problems. What we can do is look at the other languages $\langle. .$. and find their strong suits.

Персуазивность как характеристика таких типов дискурса как рекламный, судебный, политический, изучается многими авторами, обращается внимание на большой арсенал персуазивных техник и средств, применение которых варьируется в зависимости от характера речевой ситуации, а также, безусловно, от личности говорящего. Обратимся к речевым тактикам персуазивной стратегии, выделенным в материале исследования:

1. применение параллельных конструкций в сочетании с повелительным наклонением, в том числе с применением средств просодии: See what works for them. See what doesn't work for them. See what they're struggling with. See what genius ideas they have;

2. апелляция к собственному авторитету: в исследуемой презентации выступающий использует эту тактику, когда стереотипную композицию выступления, рассмотренную выше, намеренно нарушает повторным представлением себя, своего статуса в профессиональном сообществе и достижений после предъявления темы и плана презентации: A few quick words about me. I'm the founder of DevriX. We are a distributed team of fifteen people. We do extensively WordPress development <...> and other fancy things for large media websites. I've done 
some stuff with Java, with PHP, with Python, with a few other programming languages. I've been contributing to WordPress, the core platform since 3.7. Тем самым, с одной стороны, говорящий создаёт авторитетный образ языковыми средствами, с другой, композиционная аномалия, создавая экспрессивный эффект, усиливает образ;

3. апелляция к авторитетным источникам: And back to the idea of abstractions and top MVC principles <...> there's a quote by Matt Briggs, CTO at Nuvengo, a really famous stack overflow contributor, that says: "A senior developer is intimately familiar with their own failures";

4. использование экспрессивной лексики, в том числе выражающей предельную оценку: And I still do believe that WordPress is awesome; при этом, высказанное суждение подкрепляется слайдом, на котором оценочная лексема выделена, что указывает на роль средств презентационной стратегии в создании персуазивности текста, и наоборот, персуазивная лексика усиливает презентационную функцию, т.е. эффективную демонстрацию смыслов и идей.

В настоящее время в лингвистических работах идёт дискуссия о классификации коммуникативных стратегий в презентационном дискурсе. Так, А.В. Олянич ставит презентационную стратегию во главу угла: «коммуникативные стратегии сводятся исключительно к презента- ции с элементами манипуляции и конвенции» [9, с. 175]. Презентационные стратегии, при этом, понимаются в более широком смысле, как «способ производства коммуникативного пространства и способ представления этого коммуникативного пространства в среде коммуникации за счет работы по изменению структуры этой среды» [Там же].

Действительно, как показали результаты исследования, зачастую одни и те же тактики способствуют реализации одновременно более, чем одной стратегии, элементы одной стратегии встраиваются в структуру другой таким образом, что элементы презентационной стратегии могут служить реализации персуазивной и конвенциональной и наоборот. Представляются актуальными дальнейшие исследования презентационной стратегии и её соотношения с другими речевыми стратегиями. Кроме того, представляются актуальными исследования жанров деловой презентации, имеющих место в плоскости виртуального пространства в режиме видеоконференций с сокращающейся ролью кинесических и проксемических средств презентационной стратегии, увеличением дистанции между говорящим и слушающими ввиду разделённости «экраном» и пространством, затруднённой оценкой интерпретанты и перлокутивного эффекта субъектом речи, и возрастающей ролью средств просодии, а также визуальных средств электронной среды.

\section{ЛИТЕРАТУРА}

1. Блох М.Я. Философия регуляции речевого общения: от диалога личностей к диалогу культур // Вестник Иркутского государственного лингвистического университета (ИГЛУ). 2012. № 2 (18). С. 53-59.

2. Буторина Е.П. Русский язык в деловой интернет-коммуникации. Академия Естествознания, 2013. [Электронный ресурc]. URL: www.monographies.ru/ru/ book/section?id=6802 (дата обращения: 20.02.20).

3. Григорьева В.С. Дискурс как элемент коммуникативного процесса: прагмалингвистический и когнитивный аспекты: монография. Тамбов: Изд-во Тамб. Гос. техн. ун-та, 2007. 288 с.

4. Дементьев В.В. Непрямая коммуникация. Гнозис, 2006. 376 с.

5. Дементьев В.В. Теория речевых жанров. М: Знак, 2010. 600 с.

6. Дементьев В.В. Теория речевых жанров и актуальные процессы современной речи // Вопросы языкознания. 2015. № 6. С. 78-107.

7. Кушакова Н.О. Дискурсивный анализ современной sms-опосредованной коммуникации: автореф. дис....канд.филол.наук. Омск, 2016. 23 с.

8. Олянич А.В. Презентационная теория дискурса: автореферат дис. ... доктора филологических наук. Волгогр. гос. пед. ун-т. Волгоград, 2004. 40 с.

9. Олянич А.В. Рекламный дискурс // Дискурс-Пи. Екатеринбург: Институт философии и право Ур0 РАН. 2015. № 2(19). С. 173-175.

(с Медведева Юлия Ивановна (ea4english@yandex.ru). 